\title{
Comportamento estrutural de vigas de concreto reforçadas com ripas de bambu cravejadas de pinos
}

\author{
Antonio C. Braga Filho ${ }^{1}$, H umberto C. Lima Júnior ${ }^{2}$, N ormando P. Barbosa ${ }^{1} \&$ Fabio L. Willrich ${ }^{3}$
}

\section{RESUMO}

U ma das deficiências do bambu reforçando vigas de concreto armado está relacionada com deslocamentos relativos entre os dois materiais. A investigação aqui reportada teve como objetivo avaliar experimentalmente a possibilidade de se melhorar 0 trabalho conjunto bambu-concreto, através do cravejamento de pinos nas ripas de bambu usadas como reforço. Para tanto, oito vigas de concreto foram ensaiadas, das quais seis foram reforçadas com ripas de bambu Dendrocalamus giganteus Munro cravejadas de pinos e duas armadas com ripas de bambu sem a presença dos pinos, como referência. U saram-se dois tipos de pino: de aço ou de bambu, em número de dois, três ou quatro pinos entre nós. Curvas força-deslocamento e força-deformação dos materiais são apresentadas e discutidas, em que os resultados mostraram que a cravação dos pinos produziu um aumento de rigidez das vigas; contudo, o furo feito para colocação do pino reduziu localmente a seção transversal da ripa de bambu e, consequentemente, a resistência última das vigas. Finalmente, resultados similares foram obtidos em vigas reforçadas com pino de aço ou de bambu.

Palavras-chave: aderência, concreto armado, reforço não metálico, material alternativo

\section{Structural behavior of concrete beams reinforced with pinned bamboo-splints}

\begin{abstract}
0 ne drawback of bamboo as concrete reinforcement beams is the relative displacement between the two materials. The research reported in this paper aimed to experimentally investigate the improvement of bamboo-concrete-bond by means of nailing. Eight concrete beams were tested, six of them reinforced with Dendrocalamus giganteus Munro nailed bamboosplints and two reference beams, reinforced with bamboo-splints without pins. Steel pins or bamboo pins were used. Two, three and four pins were nailed between bamboo nodes. Load-displacement and load-strain curves are presented and discussed. The results showed that the pins improved the beam stiffness; nevertheless, they reduced locally the transversal section of the bamboo splint and, consequently, the ultimate load. Finally, similar results were showed by beams reinforced by steel pins or bamboo pins.
\end{abstract}

Key words: bond, reinforced concrete, non metallic reinforcement, alternative material

DEC/UFPB, CEP 58059-900, João Pessoa, PB. Fone: (81) 3246-2669 ou 8735-7061 E-mail.: antfilho2000@yahoo.com.br; npperazzo@1sr.ct.ufpb.br

${ }^{2}$ Núcleo de Tecnologia/UFPE, BR 104, km 62, S. Superior 18, Módulo Verde, Alameda Santa Cruz do Capibaribe CEP 55002970, Caruaru, PE, Fone: (81) 3727-6793. E-mail: humbertolima@ufpe.br

${ }_{3}^{3}$ Laboratório de Modelos Reduzidos/UNIOESTE, Rua Universitária 2069, CEP 85814-110, Cascavel, PR. Fone: (45) 3220-3221. E-mail: flwillrich@unioeste.br 


\section{INTRODUÇÃO}

A construção de moradias e de instalações agrícolas dignas nas áreas rurais dos países em desenvolvimento é uma necessidade sempre presente. No Brasil, particularmente na região Nordeste, a maioria das construções rurais é feita com ripas de vegetação local e com solo, sem o mínimo uso de tecnologia. Tais construções apresentam péssima aparência estética, baixa resistência às intempéries e grande número de fissuras nas quais se alojam, usualmente, insetos transmissores de doenças, o que se deve, entre outros, ao fato de que os materiais industrializados mobilizam vastos recursos financeiros, o que torna seu uso proibitivo em micropropriedades, para a população de baixa renda, razão pela qual se usam, erradamente, materiais como o solo, a madeira e o bambu, por falta de conhecimento sobre as características desses materiais; apesar disto, com tais materiais e a um custo relativamente baixo se pode obter construções seguras e duráveis (Beraldo \& Rivero, 2003; Sudin \& Swamy, 2006; De Flander \& Roversa, 2009; Bonilla et al., 2010).

O bambu é um material de construção com ótimas propriedades mecânicas e que, em pequenas construções, pode vir a reforçar elementos estruturais de concreto armado (Ghavami, 1995). Apesar disso, esta aplicação tem sido bastante limitada em virtude da baixa aderência verificada entre o bambu e o concreto. Ghavami (2005) afirmou que a baixa aderência bambu-concreto é causada pelas características higroscópicas do bambu o qual, quando em contato com a água de amassamento do concreto, absorve parte da água e incha; após o endurecimento do concreto o bambu se contrai, fato que provoca o descolamento do bambu do concreto endurecido comprometendo, assim, a aderência por adesão e por atrito entre esses materiais. Outro fato que prejudica ainda mais o mecanismo de aderência bambu-concreto é a superfície lisa do bambu. No caso de elementos estruturais de concreto armado submetidos a flexão, a redução da aderência é caracterizada pela diminuição do índice de rigidez desses elementos (Macgregor, 1997). Tentando solucionar tais problemas, diversos pesquisadores vêm realizando novas pesquisas referentes ao tema, ao redor do mundo (Lopes et al., 2002; Yu et al., 2003; Lima Jr. et al., 2005b; Mesquita et al., 2006; Lima Jr. et al., 2008; 2010).

Dentro do contexto ora apresentado, este trabalho apresenta um estudo experimental de oito vigas de concreto reforçadas com bambu, nas quais as ripas de bambu tiveram sua aderência elevada por meio da cravação de pinos de aço ou de bambu.

\section{Material e métodos}

Para a produção do concreto utilizado nas vigas, utilizaram-se: areia quartzosa com módulo de finura de 2,11 , diâmetro máximo de 2,4 mm e massa unitária de $1,62 \mathrm{~kg} \mathrm{dm}^{-3}$; agregado graúdo de origem basáltica com módulo de finura de 5,79 , diâmetro máximo de $9,5 \mathrm{~mm}$ e massa unitária de $1,52 \mathrm{~kg} \mathrm{dm}^{-}$ ${ }^{3}$ e cimento Portland branco, CPB-40, que apresentava finura Blaine de $426 \mathrm{~m}^{2} \mathrm{~kg}$.
As porcentagens dos materiais foram definidas a partir de uma curva experimental de dosagem, para a qual se adotou um teor de argamassa de $51 \%$, relação água/materiais secos de $10 \%$, abatimento no cone de Abrams de $18 \pm 2 \mathrm{~cm}$ e resistência à compressão do concreto, de $25 \mathrm{MPa}$. As resistências dos concretos foram avaliadas aos quatorze dias, por meio de ensaio de corpos-de-prova cilíndricos 15 x $30 \mathrm{~cm}$. Com base nas curvas de dosagem e na resistência pré-estabelecida, obteve-se a seguinte proporção em massa de materiais: 1:1, 86:2, 75 (cimento: agregado miúdo: agregado graúdo) e relação água cimento de 0,56 . As características dos concretos utilizados são apresentadas na Tabela 1.

Tabela 1. Propriedades do concreto

\begin{tabular}{cccccc}
\hline $\begin{array}{c}\text { Resistência } \\
(\mathrm{MPa})\end{array}$ & Traço & $\begin{array}{c}\text { Slump } \\
(\mathbf{c m})\end{array}$ & Relação a/c & $\begin{array}{c}\mathrm{f}_{\mathrm{c}}-\mathrm{s} \\
(\mathrm{MPa})\end{array}$ & $\begin{array}{c}\text { fck } \\
(\mathrm{MPa})\end{array}$ \\
25 & $1: 1,86: 2,75$ & 18 & 0,56 & $27,33-1,03$ & 25,62 \\
\hline Nota: a/c é a relação água/cimento, $\mathrm{f}_{\mathrm{cj}}$ é a resistência média do concreto, $\mathrm{f}_{\mathrm{ck}}$
\end{tabular}

é a resistência característica do concreto e s é o desvio padrão da amostra

O bambu utilizado foi da espécie Dendrocalamus giganteus Munro, cujos colmos foram cortados com idade entre dois e três anos e deixados para secar à sombra, em temperatura ambiente, durante três meses. Os colmos apresentavam comprimento médio de $20 \mathrm{~m}$ e foram divididos em três trechos de igual comprimento, denominados: basal, intermediário e topo. O bambu apresentou comportamento elástico-linear a tração até a ruptura, tanto para a região nodal como para a internodal. As resistências a tração das regiões nodal e internodal foram 97 e $277 \mathrm{MPa}$, respectivamente, e os módulos de elasticidade de 13 e $23 \mathrm{GPa}$, respectivamente.

Utilizaram-se barras de aço nervuradas com diâmetro de 8 e $5 \mathrm{~mm}$, para confecção dos pinos e estribos, respectivamente. Três amostras de $80 \mathrm{~cm}$ de comprimento, de cada diâmetro, foram coletadas para o ensaio de tração uniaxial. Os corpos-de-prova foram pesados em balança com precisão de 0,01 g, tiveram o comprimento medido e, em seguida, foram calculados as áreas transversais e os respectivos diâmetros, considerando-se a massa específica do aço igual a $7850 \mathrm{~kg} \mathrm{~m}^{-}$ 3. Após o cálculo dos diâmetros os corpos-de-prova foram instrumentados com "clip gage" e ensaiados em uma máquina universal de ensaios. As barras de 8 e $5 \mathrm{~mm}$ apresentaram tensão média de escoamento de 686 e $701 \mathrm{MPa}$, respectivamente, e módulo de elasticidade médio de 222 e 215 GPa, respectivamente.

\section{Característica dos corpos-de-prova}

Para realização do programa experimental selecionaram-se duas variáveis de influência: tipo de pino utilizado (de aço ou de bambu) e o número de pinos cravados nas regiões dos internódios (2, 3 e 4). Para cada combinação de variável foi preparada e ensaiada uma viga, resultando em um programa de 6 vigas; além das seis vigas armadas longitudinalmente com ripas de bambu, utilizaram-se os resultados de duas vigas ensaiadas por Lima Jr. et al. (2005a) armadas com ripas de bambu sem cravação de pinos e que serviram de referência para o presente estudo. 
As seis vigas apresentavam seção transversal retangular com $25 \mathrm{~cm}$ de altura e $10 \mathrm{~cm}$ de largura, comprimento de $260 \mathrm{~cm}$ e vão teórico de $250 \mathrm{~cm}$, e todas foram dimensionadas de modo a apresentar colapsos por flexão, com ruptura da amadura longitudinal; assim, utilizaram-se armaduras transversais que se compunham de estribos de dois ramos, com $5 \mathrm{~mm}$ de diâmetro e espaçados a cada $10 \mathrm{~cm}$ na região de flexão pura e a cada $7 \mathrm{~cm}$ na região de flexão simples. Objetivando-se evitar a condição de colapso por esmagamento do concreto; a resistência à compressão do concreto foi tomada como igual a $25 \mathrm{MPa}$.

Para preparação das armaduras das seis vigas de bambu, os colmos de bambu foram selecionados após secagem; em seguida, foram levados a uma marcenaria para serem serrados em serra circular para se extrair, dos colmos, ripas com comprimento de $2,6 \mathrm{~m}$ e seções transversais retangulares com largura de $2 \mathrm{~cm}$ e espessura igual à da parede do bambu; após o corte as ripas foram escovadas e limpas e depois tiveram suas seções transversais medidas com paquímetro de $0,01 \mathrm{~mm}$ de sensibilidade a cada $25 \mathrm{~cm}$. Ao final desses procedimentos as ripas de bambu foram selecionadas para a montagem das armaduras, tendo-se o cuidado, porém, de manter os nós em posições intercaladas. Antes da montagem algumas ripas de bambu foram furadas com uma furadeira elétrica e broca de $8 \mathrm{~mm}$; em seguida, pinos de aço e de bambu, com igual diâmetro, foram cravados nos furos. Na Figura 1 se apresentam detalhes das ripas de bambu com os pinos cravados e da amadura das vigas após montagem.

A.

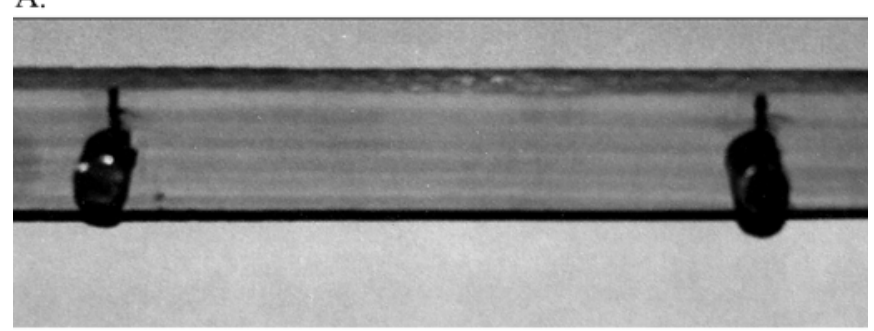

B.

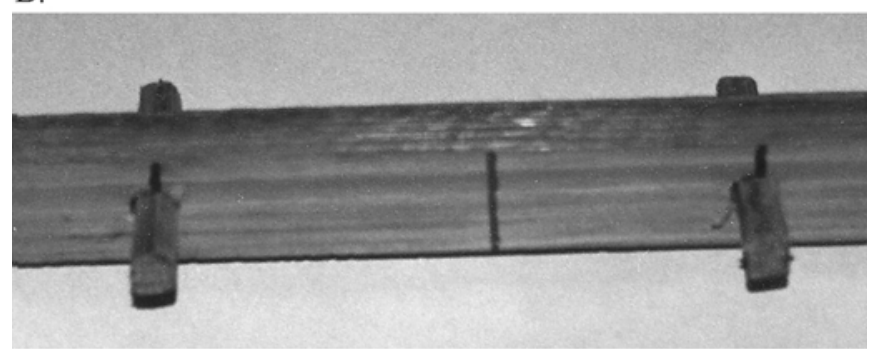

Figura 1. D etalhes das ripas de bambu: A) com pinos de aço e B) com pinos de bambu

As vigas de referência foram armadas com duas ripas de bambu de $2 \mathrm{~cm}$ x espessura sem a presença de pinos (vigas 1 e 2); duas vigas com ripas de bambu com dois pinos por internódio de bambu e de aço (vigas 3 e 4, respectivamente); duas vigas com ripas de bambu com três pinos por internódio de bambu e de aço (vigas 5 e 6 , respectivamente) e, por fim, duas vigas com ripas de bambu com quatro pinos por internódio de bambu e de aço (vigas 7 e 8, respectivamente). Na Figura 2 se apresentam os detalhes das armaduras utilizadas nas vigas.

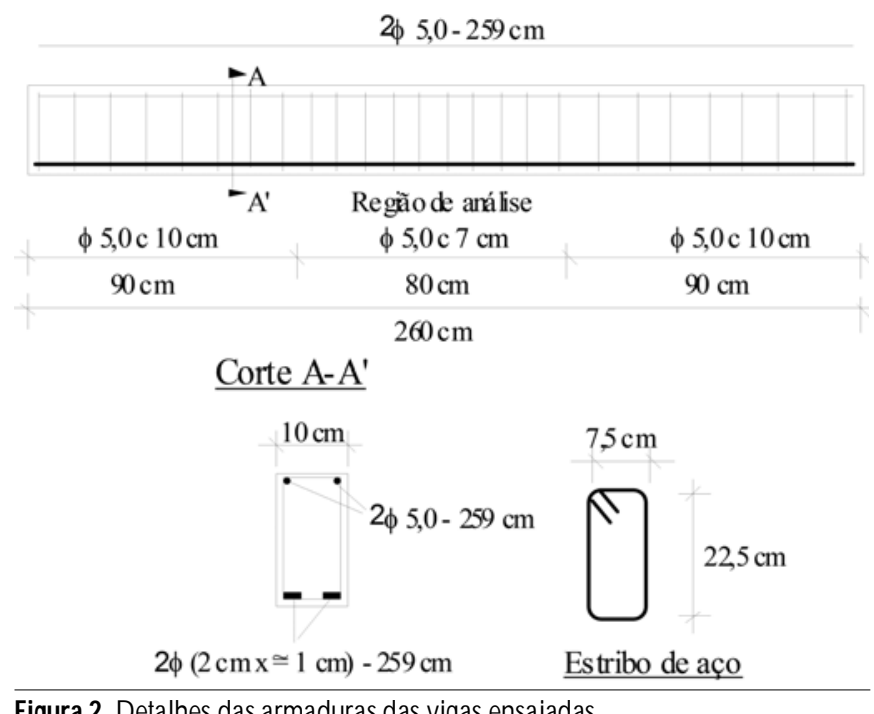

Figura 2. D etalhes das armaduras das vigas ensaiadas

As vigas foram moldadas em formas metálicas, sendo o concreto vibrado mecanicamente por meio de vibrador de agulha; após a concretagem, espumas molhadas foram dispostas sobre as vigas, durante $24 \mathrm{~h}$ para, logo depois, as vigas serem desenformadas, regadas com água e cobertas por lona plástica, permanecendo assim pelo período 7 dias. Por ocasião da concretagem de cada viga três corpos-de-prova cilíndricos 150 x $300 \mathrm{~mm}$ foram moldados para avaliação da resistência a compressão e depois submetidos ao mesmo processo de cura das vigas; em seguida a este processo, as vigas foram preparadas para o ensaio, que ocorreu aos 14 dias após a concretagem; por fim, a resistência a compressão do concreto nos dias dos ensaios das vigas está apresentada na Tabela 1 e, na Figura 3, tem-se detalhes das armaduras posicionadas dentro das formas.

\section{Metodologia de ensaio}

As vigas foram ensaiadas em uma mesa de reação com capacidade de carga de $300 \mathrm{kN}$. O carregamento foi aplicado em quatro pontos, dois ativos e dois reativos, por meio de dois cilindros hidráulicos. O vão livre foi de $2,5 \mathrm{~m}$. O sistema de carga utilizado garantia que as forças aplicadas nos dois cilindros fossem as mesmas. Células de carga com capacidade de $100 \mathrm{kN}$ foram conectadas aos cilindros hidráulicos. O controle de carregamento foi manual a partir da força aplicada enquanto o carregamento foi aplicado de modo quase estático, monotonicamente, e as leituras dos instrumentos realizadas a cada $2,5 \mathrm{kN}$. Utilizaram-se três medidores mecânicos de deslocamento, com sensibilidade de 0,01 mm, a fim de avaliar as deflexões abaixo dos pontos de aplicação das forças e na seção transversal central das vigas, além de dois extensômetros de resistência elétrica para medir as deformações no concreto e na armadura longitudinal, no meio do vão, ressaltando-se que um foi disposto em uma das barras da armadura longitudinal e o outro na face superior das vigas 

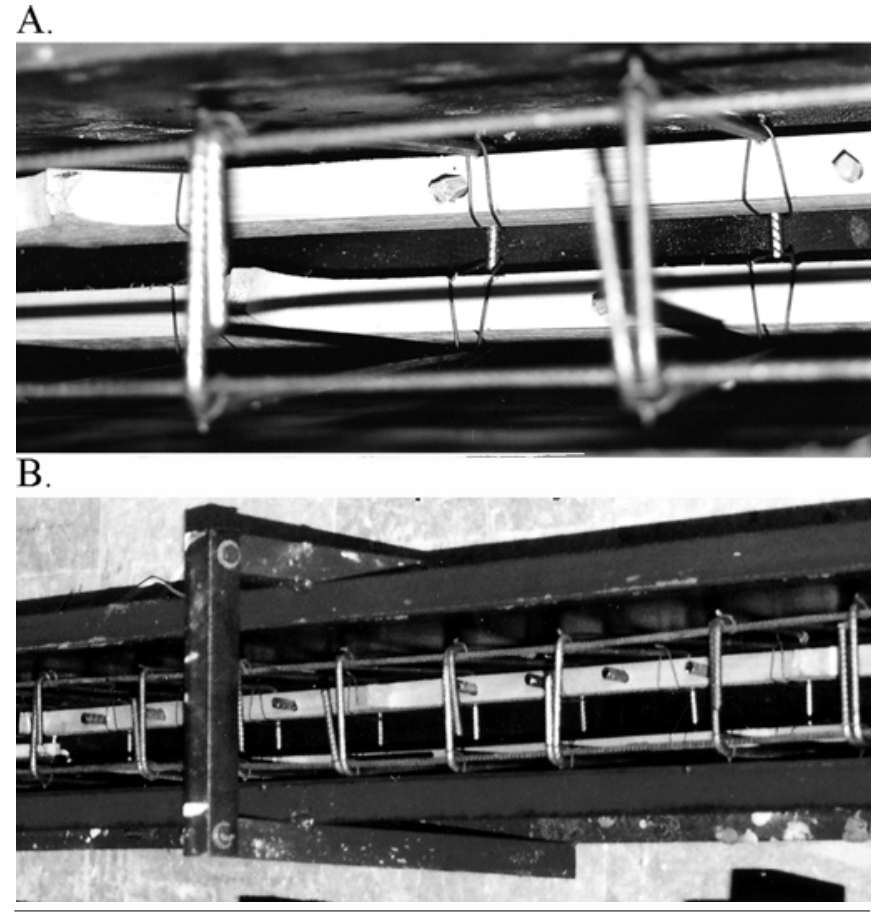

Figura 3. D etalhes das armaduras posicionadas dentro das formas metálicas: A) armadura com pinos de bambu e B) armadura com pinos de aço

no concreto. Realizaram-se leituras de abertura de fissuras de cisalhamento e de flexão, constantemente, por fissurômetro, com lente de aumento de 20 vezes. Detalhes do ensaio e instrumentação são apresentados nas Figuras 4 e 5.

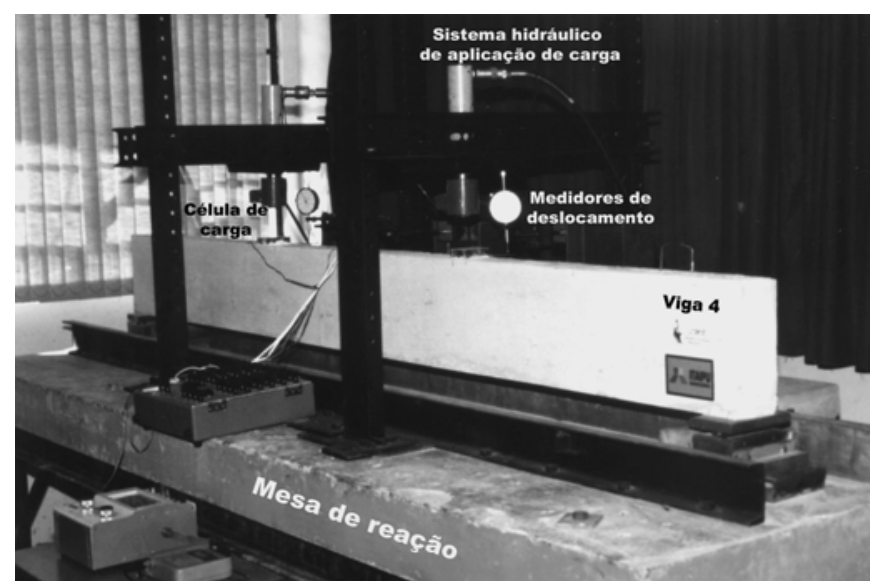

Figura 4. Detalhe do ensaio das vigas

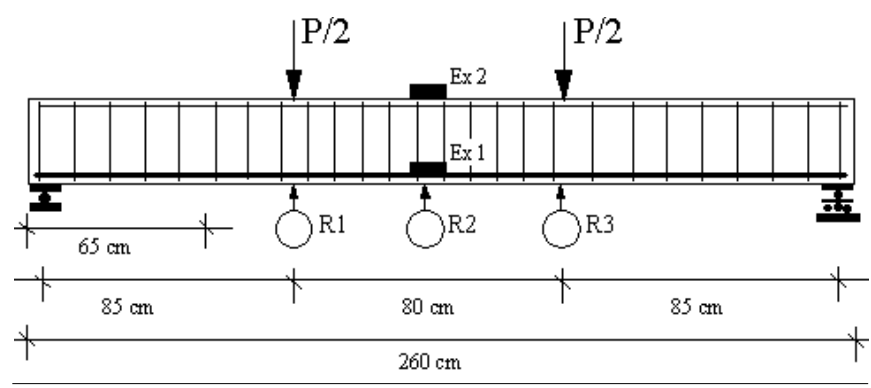

Figura 5. Detalhes da instrumentação

\section{RESULTADOS E DISCUSSÃO}

\section{Comportamento geral}

As resistências dos concretos dos corpos-de-prova ficaram próximas da resistência pré-estabelecida, de $25 \mathrm{MPa}$, e a variação das resistências dos concretos entre as vigas foi desprezível, mesmo se considerando as resistência dos concretos das vigas de referencia, observando-se desvio padrão global de 1,03 MPa e resistência média global do concreto de 27,33 MPa. Em todas as concretagens os concretos apresentaram boa trabalhabilidade, com abatimento médio no cone
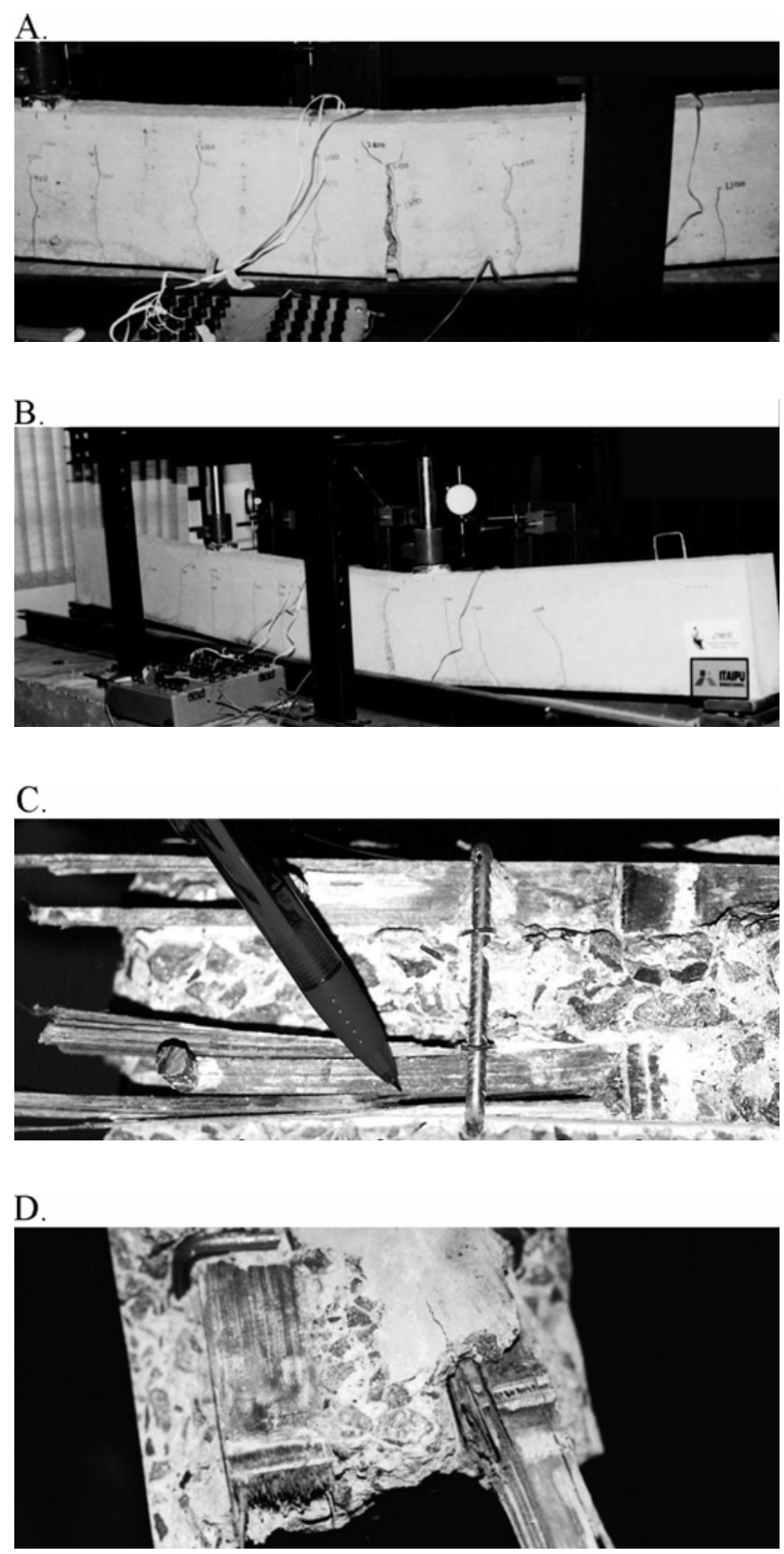

Figura 6. Detalhe do modo de colapso típicos das vigas: A) colapso da viga 5, B) colapso da viga $1, C$ ) ruptura da armadura com pino de aço e D) ruptura da armadura de bambu sem pino 
A.

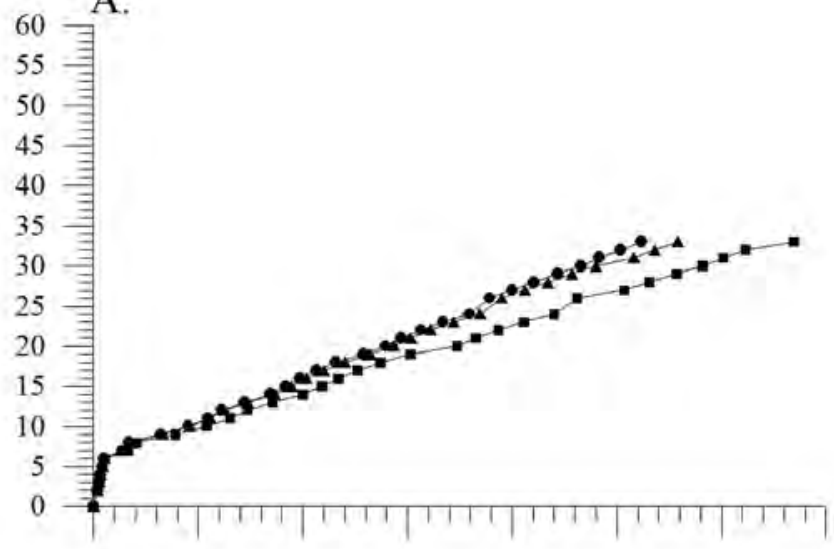

C.

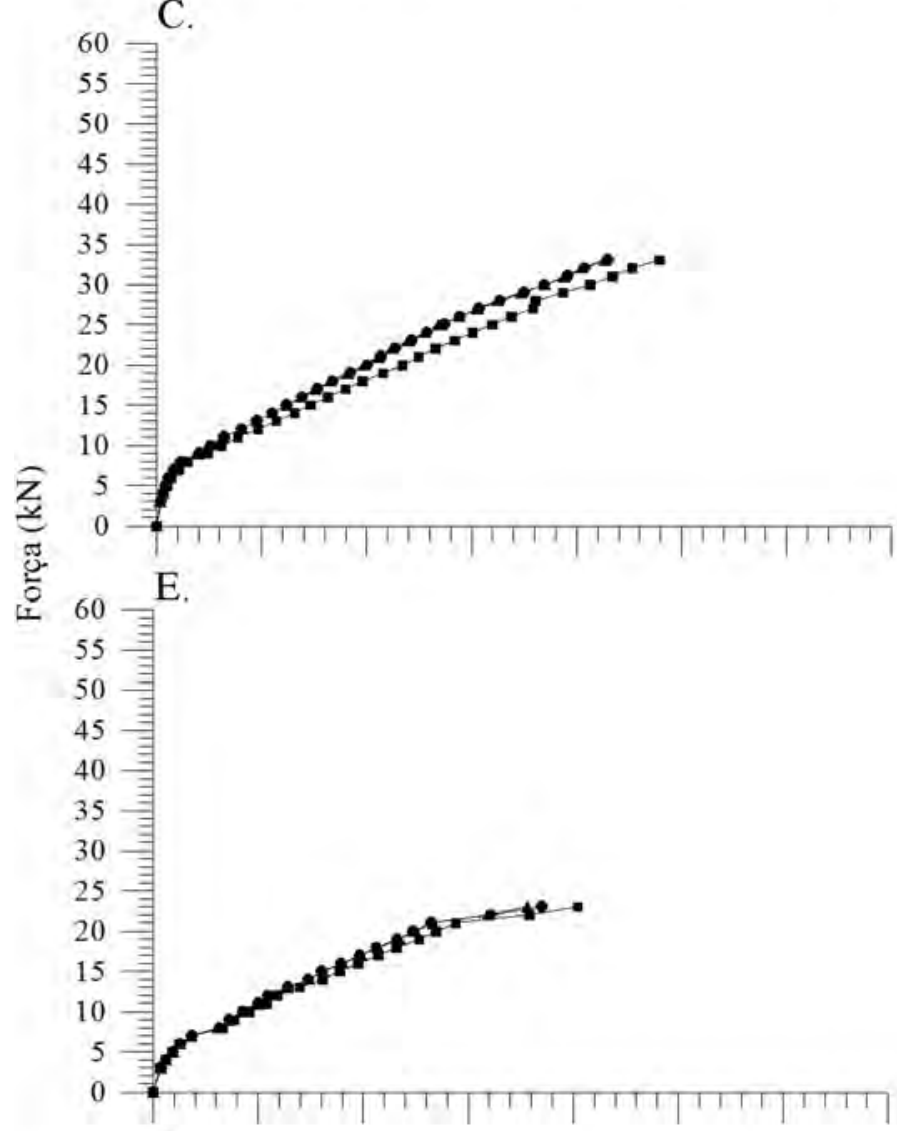

G.

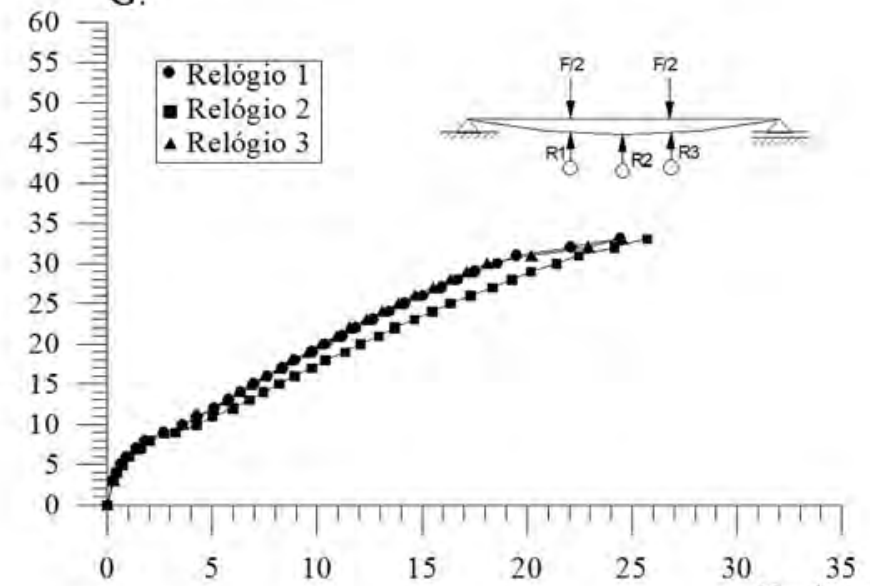

B.

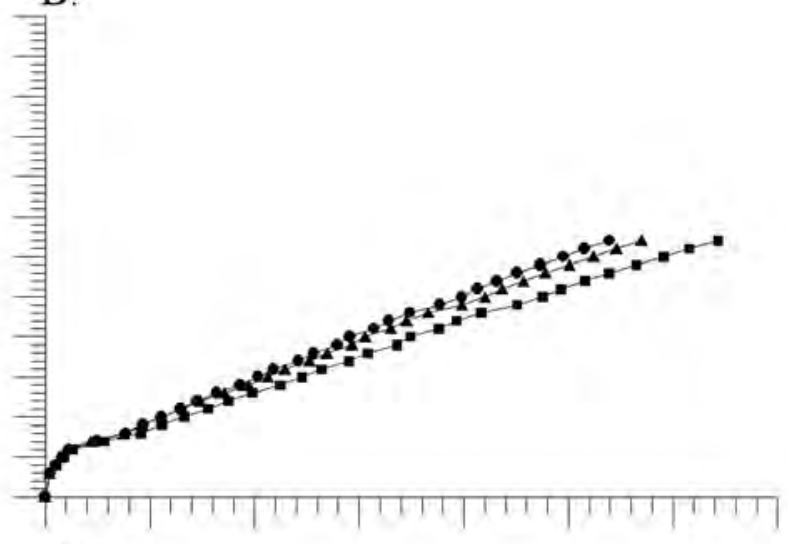

D.

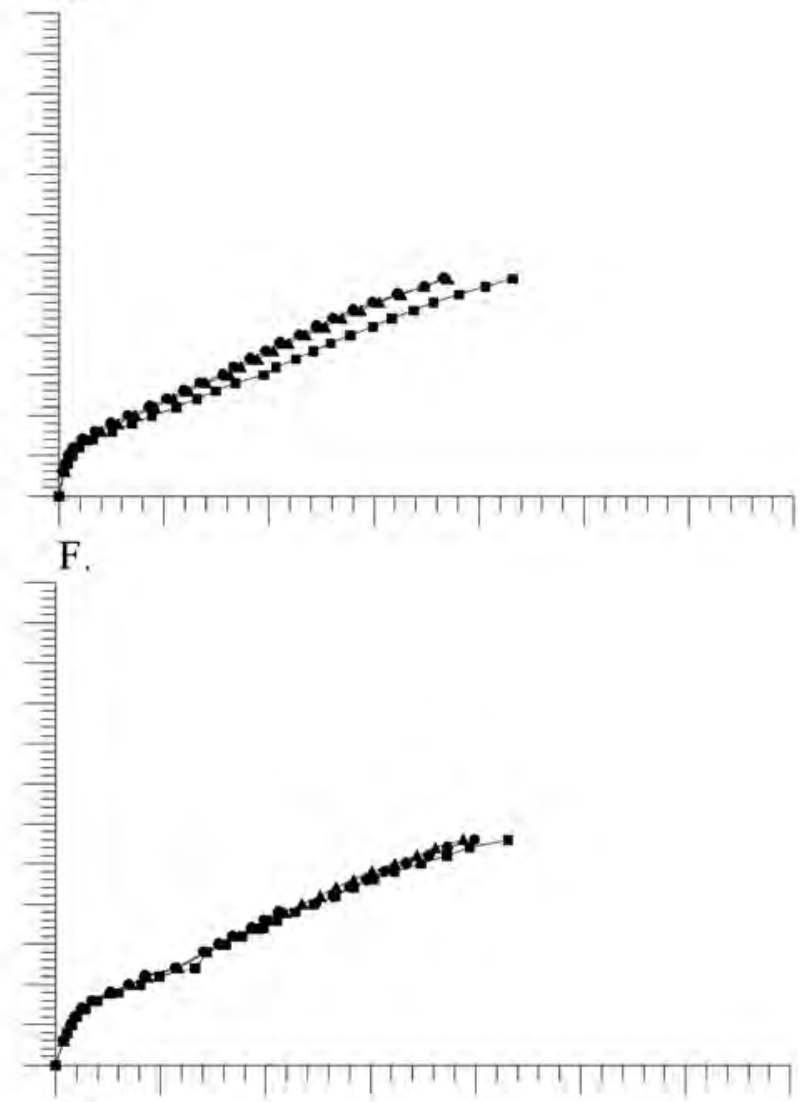

$\mathrm{H}$.

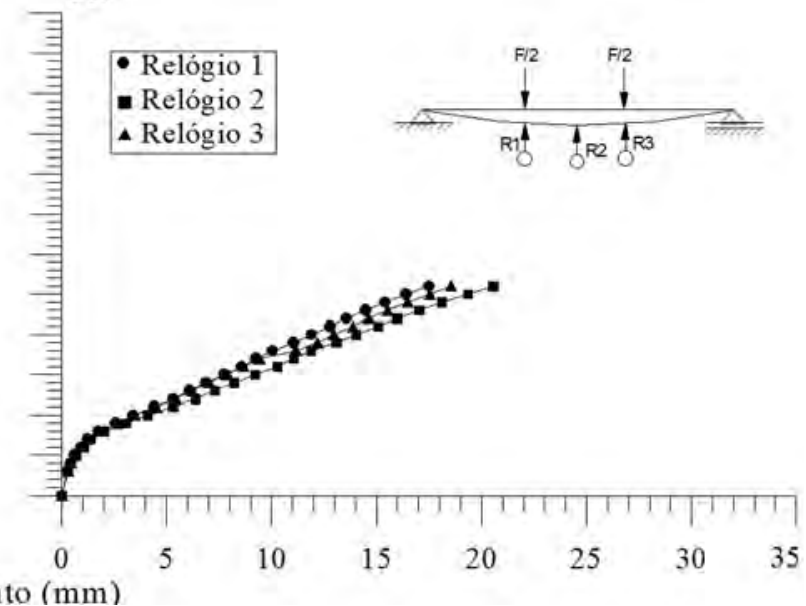

Figura 7. Diagrama força versus deslocamento transversal das vigas: A) viga 1, B) viga 2, C) viga 3, D) viga 4, E) viga 5, F) viga 6, G) viga 7 e H) viga 8 
de Abrams de $18 \mathrm{~cm}$. Na Tabela 1 se encontram as resistências médias dos concretos das vigas.

Os procedimentos de ensaio se mostraram adequados. Todas as vigas apresentaram colapso por tração excessiva na armadura longitudinal, com seção de ruptura dentro da região de análise; em todas as vigas o colapso foi caracterizado por ruptura da armadura de tração de bambu, sempre na região nodal, para as vigas sem pino e sempre na região do pino, para as vigas com pino. Constatou-se, deste modo, que a seção de colapso nem sempre foi a posicionada no meio do vão teórico; contudo, esta seção sempre permaneceu dentro da região de flexão pura. Finalmente, observou-se um espaçamento de fissuras médio para as vigas de bambu de $15 \mathrm{~cm}$. Na Figura 6 se notam alguns detalhes do modo característico de colapso das vigas.

\section{Comportamento força vs. deslocamento}

Na Figura 7 se apresentam as curvas força vs. deslocamento das vigas de bambu e se observa que os deslocamentos obtidos nos três medidores foram muito próximos cujo comportamento, bastante simétrico entre os três pontos de medição, é apresentado por todas as vigas. Na Figura 8 se acham as curvas força vs. deslocamento no meio do vão de todas as vigas. Observa-se melhora na rigidez das vigas com pino em relação às vigas de referência, caracterizada pelo aumento da inclinação das curvas, principalmente após as primeiras fissuras. Este fato, segundo Macgregor (1997), é a principal característica de melhora de aderência entre o reforço e o concreto. Ainda Mesquita et al. (2006) estudaram a aderência entre ripas de bambu cravejada com pinos e o concreto; neste estudo, os referidos autores constatam, realmente, a eficiência dos pinos na melhora da aderência bambu-concreto, resultados esses que concordam com os encontrados no presente trabalho.

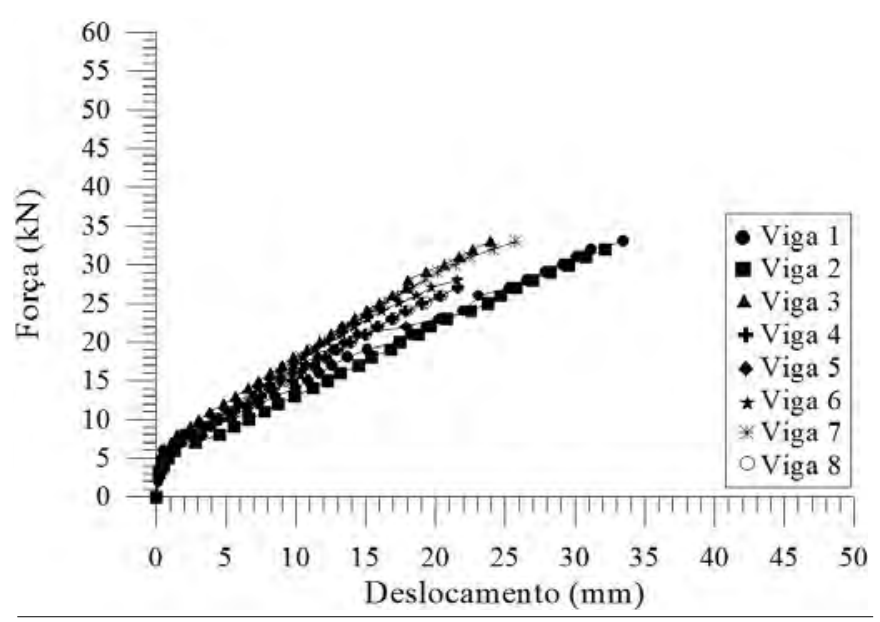

Figura 8. Diagrama força versus deslocamento transversal no meio do vão das vigas: $1,2,3,4,5,6,7$ e 8

Verifica-se que as vigas com ripas cravejadas com pinos de bambu e aço apresentaram o mesmo comportamento, não se constatando qualquer melhora no aumento de rigidez nem na capacidade resistente das vigas com pinos de aço em relação às com pinos de bambu; não se observaram, tampou- co, variações no comportamento mecânico das vigas com a elevação do número de pinos. Tais constatações discordam das apresentadas por Mesquita et al. (2006) que observaram um ganho da ordem de $30 \%$ na tensão de aderência entre o bambu e o concreto quando se utilizavam pinos de aço ao invés dos de bambu.

Com exceção das vigas 3 e 7, as demais apresentaram força última inferior às de referência, fato decorrente da redução da taxa de seção transversal das ripas de bambu provocada pelo furo para a cravação dos pinos. Essa constatação foi comprovada após ensaio e com exposição das armaduras de todas as vigas na região da ruptura das ripas. Em todas as vigas com pinos a ruptura do bambu sempre ocorreu nas regiões das ripas que continham os pinos, o que é mostrado na Figura 6.

A Tabela 2 apresenta as forças últimas e a rigidez das vigas. Obtiveram-se os índices de rigidez por meio de análise da regressão linear, considerando-se o trecho da curva entre 5 a $15 \mathrm{~mm}$ de deslocamento, correspondendo à relação entre a força aplicada e o deslocamento central da viga. Em todos os casos coeficientes de correlação, $\mathrm{R}^{2}$, superiores a $97 \%$ foram obtidos. Observa-se que a introdução de dois pinos nas ripas de bambu aumentou a rigidez da viga; todavia, o aumento do número de pinos de 2 para 4 praticamente não interfere no índice de rigidez fato este também observado por Mesquita et al. (2006) em ensaios de aderência bambu-concreto. Os coeficientes de correlação entre o aumento do número de pinos (2 para 4) e o índice de rigidez das vigas, foram inferiores a $50 \%$, tanto para as vigas com pinos de aço quanto para aquelas com pinos de bambu, significando baixa influência. Em adição, nota-se que praticamente não houve diferença nos índices de rigidez entre as vigas com pinos de aço ou de bambu; deste modo, é mais econômico utilizar pinos de bambu. A ABNT (2004) limita os deslocamentos das vigas de concreto armado, considerando apenas as cargas acidentais, ao valor do vão teórico dividido por 350 que, para o caso das vigas ensaiadas, é de 7,4 mm; desta forma, e se considerando as forças resistentes das vigas de referência correspondentes a este deslocamento, obtém-se o valor médio com o correspondente desvio padrão iguais a $11 \pm 1,4 \mathrm{kN}$; já as vigas com pinos apresentaram valor médio com o correspondente desvio padrão de $13,4 \pm 1,0 \mathrm{kN}$, ou seja, um aumento de $20 \%$ na capacidade de carga de utilização.

Constata-se, por fim, que a introdução de pinos nas ripas de bambu reduziu em média $13 \%$ a força última resistente das vigas. Esta diminuição na capacidade resistente das vigas se deve à redução da taxa de armadura longitudinal em $20 \%$ nas seções transversais que contêm a presença de um pino, como mencionado anteriormente.

Tabela 2. Índice de rigidez e força última das vigas reforçadas com bambu

\begin{tabular}{|c|c|c|c|c|}
\hline \multirow{2}{*}{ Tipo de pino } & \multicolumn{2}{|c|}{ Índice de rigidez $\left(\mathrm{kN} \mathrm{mm}^{-1}\right)$} & \multicolumn{2}{|c|}{ Força última (kN) } \\
\hline & Aço & Bambu & Aço & Bambu \\
\hline Sem pino & 0,8545 & 0,9114 & 33 & 32 \\
\hline 2 pinos & 1,0629 & 1,1688 & 27 & 33 \\
\hline 3 pinos & 1,0945 & 1,0859 & 28 & 23 \\
\hline 4 pinos & 1,0152 & 1,2145 & 26 & 33 \\
\hline
\end{tabular}




\section{Comportamento força vs. deformação}

Tem-se, na Figura 9, a curva força vs. deformação na armadura de bambu na seção transversal no meio do vão teórico das vigas. Pode-se verificar uma pequena diferença entre as deformações do bambu correspondente à força última nas vigas sem pino, na qual a deformação última média e o correspondente desvio-padrão foram de 8,92 e 0,09\%o, respectivamente. Observa-se, ainda, que nas vigas com pino as deformações últimas do bambu foram inferiores às das vigas de referência, e apresentaram valor médio e desvio-padrão iguais a 4,10 e 0,95\% . Com a cravação dos pinos, a área da seção transversal da ripa de bambu na região do furo foi reduzida em 40\%; deste modo ocorre uma concentração de tensões e, consequentemente, de deformação, nessas regiões. Considerando o exposto e que os medidores de deformação foram instalados em regiões das ripas sem a presença dos furos, previa-se que a deformação última medida apresentasse valores da ordem de 5\%, o que foi constatado.

Como as vigas foram dimensionadas para apresentar colapso por flexão com ruptura da armadura longitudinal, previa-se que as deformações do concreto fossem inferiores à deformação de ruptura desse material que, em flexão, é da ordem de 3,5\%o. Na Figura 9 se mostram os diagramas força vs. deformação do concreto na seção transversal posiciona-

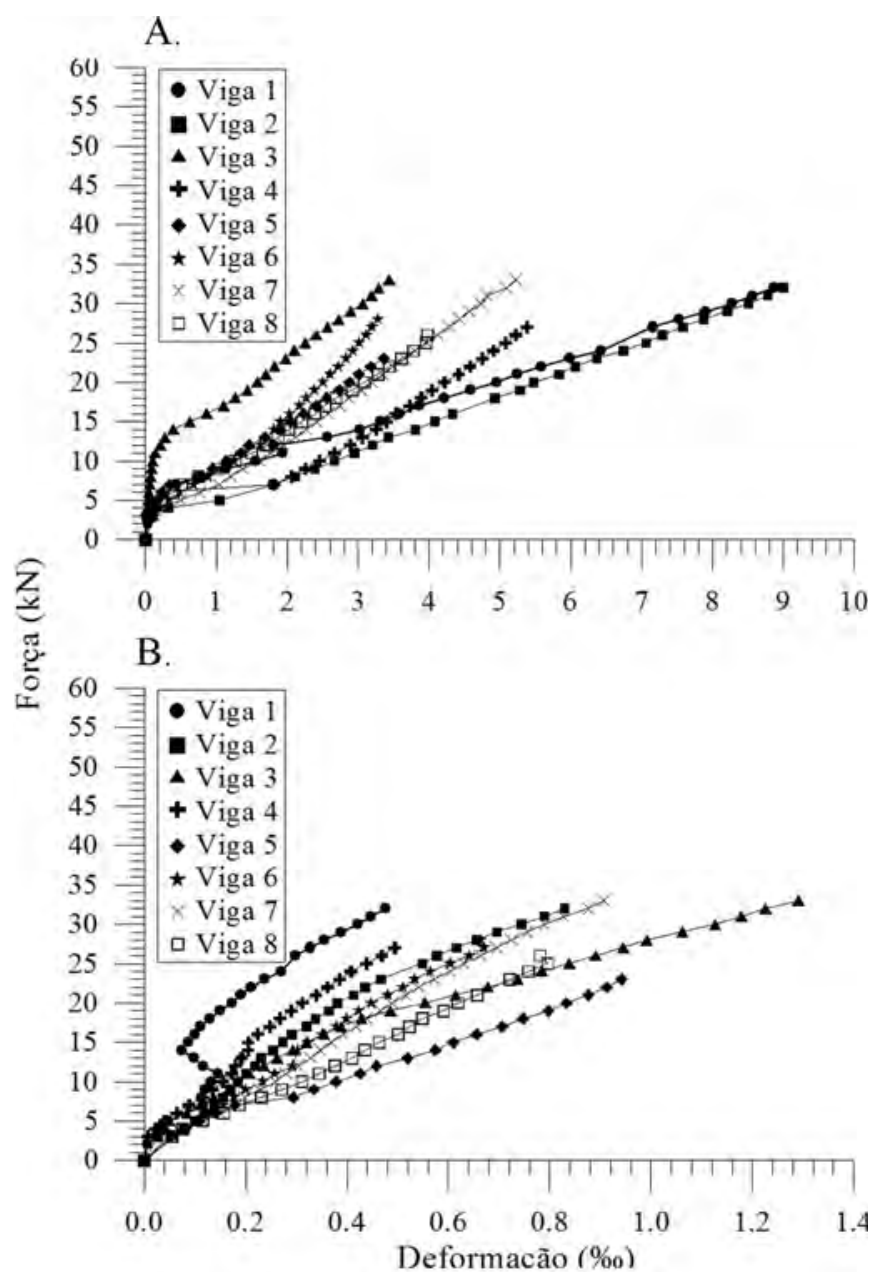

Figura 9. Diagramas força versus deformação: A) do bambu e B) do concreto na seção transversal posicionada no meio do vão teórico das vigas da no meio do vão teórico, nos quais se pode constatar que em todas as vigas a deformação máxima do concreto não ultrapassou o valor de $1,5 \%$.

\section{CONCLUSÕES}

1. A introdução de pinos aumentou o índice de rigidez das vigas.

2. Com o aumento do número de pinos não se observou o aumento do índice de rigidez.

3. O comportamento estrutural das vigas armadas com ripas de bambu cravadas com pinos de aço e bambu foi praticamente similar.

4. Verificou-se que a cravação de pinos reduziu a força última resistente das vigas; deste modo, é fundamental a intercalação da posição dos pinos entre as ripas de bambu para que uma mesma seção transversal da viga não tenha a presença de mais de um pino.

\section{AGRADECIMENTOS}

Ao CNPq, pela concessão da bolsa de mestrado concedida ao primeiro autor; os autores são gratos ao Laboratório de Concreto da Hidrelétrica de Itaipu, por ter colaborado nos ensaios experimentais realizados no Laboratório de Modelos Reduzidos da UNIOESTE.

\section{LITERATURA CITADA}

ABNT - Associação Brasileira de Normas Técnicas. NBR6118 Projeto de estruturas de concreto: Procedimentos. Rio de Janeiro: ABNT, 2004. 232p.

Beraldo, A. L.; Rivero, L. A. Bambu laminado colado (BLC). Floresta e Ambiente, v.10, n.2, p.36-46, 2003.

Bonilla, S. H.; Guarnetti, R. L.; Almeida, C. M. V. B.; Giannetti, B. F. Sustainability assessment of a giant bamboo plantation in Brazil: exploring the influence of labour, time and space. Journal of Cleaner Production, v.18, n.1, p.83-91, 2010.

De Flander, K.; Roversa, R. One laminated bamboo-frame house per hectare per year. Construction and Building Materials, v.23, n.1, p.210-218, 2009.

Ghavami, K. Ultimate load behavior of bamboo-reinforced lightweight concrete beams. Cement and Concrete Composites, v.17, n.4, p.259-351, 1995.

Ghavami, K. Bamboo as reinforcement in structural concrete elements. Cement and Concrete Composites, v.27, p.637-649, 2005.

Lima Jr., H. C.; Mesquita, L. P.; Fabro, G.; Willrich, F. L.; Czarnieski, C. J. Vigas de concreto reforçadas com bambu Dendrocalamus giganteus. I: Análise experimental. Revista Brasileira de Engenharia Agrícola e Ambiental, v.9, n.4, p.642651, 2005a.

Lima Jr., H. C.; Willrich, F. L.; Barbosa, N. P.; Rosa, M. A.; Cunha, B. S. Durability analysis of bamboo as concrete reinforcement. Materials and Structures, v.41, p.805-999, 2008. 
Lima Jr., H. C.; Willrich, F. L.; Fabro, G. Vigas de concreto reforçadas com bambu Dendrocalamus giganteus. II: modelagem e critérios de dimensionamento. Revista Brasileira de Engenharia Agrícola e Ambiental, v.9, n.4, p.652-659, 2005 b.

Lima Jr., H. C.; Willrich, F. L.; Fabro, G.; Rosa, M. A.; Tanabe, L. K.; Sabino, R. B. G. Análise mecânica de pilares mistos bambu-concreto. Revista Brasileira de Engenharia Agrícola e Ambiental, v.14, n.5, p.545-553, 2010.

Lopes, W. G. R.; Freire, W. J.; Ferreira, G. C. S. Ensaios de arrancamento e de empuxamento aplicados a taliscas de bambu. Revista Brasileira de Engenharia Agrícola e Ambiental, v.6, n.3, p.504-510, 2002.
Macgregor, J. G. Reinforced concrete, mechanics and design. New Jersey: Prentice Hall, 1997. 939p.

Mesquita, L. P.; Czarnieski, C. J.; Braga Filho, A. C.; Willrich, F. L.; Lima Jr., H. C.; Barbosa, N. P. Determinação da tensão de aderência do bambu-concreto. Revista Brasileira de Engenharia Agrícola e Ambiental, v.10, n.2, p.505-516, 2006.

Sudin, R.; Swamy, N. Bamboo and wood fibre cement composites for sustainable infrastructure regeneration. Journal of Materials Science, v.41, n.21, p.6917-6924, 2006.

Yu, W. K.; Chung, K. F.; Chan, S. L. Column buckling of structural bamboo. Engineering Structures, v.25, p.755-768, 2003. 